\title{
Continuous Ground-Based Observation of Aerosol Optical Properties at Tsukuba, Japan: Trend and Climatology
}

\author{
Akihiro UCHIYAMA, Akihiro YAMAZAKI, Rei KUDO, Eriko KOBAYASHI ${ }^{1}$, \\ Hiroki TOGAWA ${ }^{2}$, and Daisaku UESAWA
}

Meteorological Research Institute, Japan Meteorological Agency, Tsukuba, Japan

(Manuscript received 4 November 2013, in final form 30 May 2014)

\begin{abstract}
To investigate aerosol optical properties, the Meteorological Research Institute has been continuously measuring scattering and absorption coefficients since January 2002 by using an integrating nephelometer and one- and three-wavelength absorption photometers in dry air conditions at Tsukuba, Japan. We used these optical data to investigate trends of aerosol properties and climatology from 2002 to 2013. The results showed that most aerosol characteristics had seasonal variation and decreasing or increasing trends significant at the $95 \%$ confidence level. From 2002 to 2013, the extinction coefficient at $550 \mathrm{~nm}$ and absorption coefficient at $530 \mathrm{~nm}$ had statistically significant decreases of $-1.5 \times 10^{-6}$ and $-5.4 \times 10^{-7} \mathrm{~m}^{-1}$ year ${ }^{-1}$, respectively. In the same period, the scattering coefficient showed a non-significant decrease of $-8.8 \times 10^{-7} \mathrm{~m}^{-1}$ year ${ }^{-1}$. The single scattering albedo (SSA) at 550 $\mathrm{nm}$ had a significant increasing trend of $7.4 \times 10^{-3}$ year $^{-1}$. Asymmetry factors did not show a significant trend. The increasing trend in the extinction Ångström exponent was significant, whereas the trend in the effective radius was not significant. The increasing trend of $2.1 \times 10^{-2}$ year $^{-1}$ in the absorption Ångström exponent from 2006 to 2013 was significant. This tendency suggests a compositional change of light-absorbing aerosol. Frequency distributions of aerosol properties were investigated during 2006-2012. In this period, absorption coefficients were measured by the three-wavelength absorption photometer. The most frequent values of the extinction coefficient at $550 \mathrm{~nm}$, the absorption coefficient at $530 \mathrm{~nm}$, and the SSA at $550 \mathrm{~nm}$ were $25 \times 10^{-6}, 3.0 \times 10^{-6} \mathrm{~m}^{-1}$, and 0.905 , respectively. The analysis using the extinction Ångström exponent showed that aerosol characteristics were dependent on the extinction Ångström exponent. The aerosol characteristics estimated from optical data were consistent with those derived from radiometer data. Therefore, ground-based monitoring of aerosol optical properties is useful for monitoring aerosol characteristics and interpreting variations in the surface radiation budget.
\end{abstract}

Keywords aerosol optical property trend; aerosol optical property climatology; single scattering albedo; aerosol scattering coefficient; aerosol absorption coefficient

Corresponding author: Corresponding author: Akihiro Uchiyama, Meteorological Research Institute, Japan Meteorological Agency, 1-1, Naganine, Tsukuba, Ibaraki 305-0052, Japan

E-mail: uchiyama@mri-jma.go.jp

${ }^{1}$ Present affiliation: Aerological Observatory, Japan Meteorological Agency

${ }^{2}$ Present affiliation: Tokyo District Meteorological Observatory, Japan Meteorological Agency

(C)2014, Meteorological Society of Japan

\section{Introduction}

Aerosol characteristics are an important factor in the Earth's radiation budget. The Earth's radiation budget is influenced by radiatively active gases, aerosols, and clouds. Aerosols change the radiation budget directly by absorbing and scattering solar radiation and indirectly through their role as cloud condensation nuclei $(\mathrm{CCN})$, thereby increasing cloud reflectivity and lifetimes (e.g., Ramanathan et al. 2001; Lohmann and Feichter 2005). 
The surface radiation budget has variability at the decadal scale (Wild 2009). Long-term observations of surface solar radiation revealed a decreasing trend, called global dimming, from the early 1950s to the late 1980s (Gilgen et al. 1998; Liepert 2002; Wild et al. 2004; Wild 2009) and an increasing trend, called global brightening, in the 1990s (Wild et al. 2005, 2007, 2008; Pinker et al. 2005; Dutton et al. 2006; Gilgen et al. 2009; Wild 2009). In Japan, likewise, surface solar radiation decreased until the mid-1980s and increased thereafter (Wild et al. 2005; Ohmura 2009), and the rate of increase has decreased more recently (Wild et al. 2009; Kudo et al. 2012). The variation in the observed surface solar radiation depends on the presence of clouds, aerosols, and radiatively active gases.

At the Meteorological Research Institute (MRI), we are investigating the influence of aerosol optical properties through observations of surface solar radiation and direct measurements of aerosol optical properties (scattering coefficients and absorption coefficients) at a ground-based observation site in Tsukuba, Japan. On the basis of surface solar radiation data, Kudo et al. $(2011,2012)$ reported that decadal variation from the 1970s to 2000s in Japan could be explained by variations in aerosol optical depth and single scattering albedo (SSA) rather than by changes in clouds.

The objectives of this study are to investigate the most recent 10 years of aerosol optical properties measured at Tsukuba and to show the climatological characteristics of the Japan region. These data consist of optical scattering and absorption coefficients of aerosol. The aerosol composition is not measured; therefore, we can not address the relationship between composition and optical properties. This paper concentrates on the observational evidence bearing on the aerosol optical properties.

In the 1970s, the importance of aerosol optical properties was recognized (e.g., Yamamoto and Tanaka 1972), and measurement programs were begun at several locations (e.g., South Pole, Mauna Loa, Point Barrow; McComiskey et al. 2004). Awareness of the effect of aerosols on climate radiative forcing led to an increase in the number of measured variables and measurement sites in the 1990s.

Coen et al. (2007) analyzed data from the alpine Jungfraujoch station in Switzerland (JFJ; $3580 \mathrm{~m}$ asl), where measurements of a comprehensive set of aerosol variables began in 1995, and described an increasing trend in light-scattering coefficients during the September to December period. Junker et al. (2006) reported the trends and seasonal characteristics of aerosol light absorption at the Mace Head Atmospheric Research station near Carna, Ireland, where aerosol measurements based on light attenuation in fiber filters have been conducted since 1989. Sheridan et al. (2001) reported the results of 4 years of continuous measurement of aerosol optical and microphysical properties at the U.S. Department of Energy's Atmospheric Radiation Measurement (ARM) Program Southern Great Plains Cloud and Radiation Testbed (CART) site.

We began test measurements of aerosol optical properties at the MRI in 2001, and have performed continuous measurements since 2002. Scattering coefficients are measured with a three-wavelength nephelometer (TSI model 3563), and absorption coefficients were initially measured with a Particle Soot/Absorption Photometer (PSAP), and beginning in 2006, they have been measured with a three-wavelength PSAP (PSAP3 $\lambda$ ) (both by Radiance Research).

In this paper, the data we used are described in Section 2, and analytical methods are described in Section 3. Section 4 presents the 10 -year trends in aerosol optical properties, frequency distribution of aerosol optical properties, and an analysis of aerosol properties using the extinction Ångström exponent. Our results are summarized in Section 5.

\section{Data}

Scattering coefficients were measured from January 2002 to July 2013 by a nephelometer (TSI model 3563, described by Anderson et al. 1996) using 30min averages. The nephelometer measures scattering coefficients and hemispheric back-scattering coefficients at wavelengths of 450,550 , and $700 \mathrm{~nm}$. The measurement angle ranges of scattering coefficients and hemispheric back-scattering coefficients are $7^{\circ}$ to $170^{\circ}$ and $90^{\circ}$ to $170^{\circ}$, respectively. Because aerosol scattering coefficients are affected by relative humidity, it is difficult to measure them reliably in open air. Therefore, we measured scattering coefficients in dry air conditions when relative humidity was less than $50 \%$.

Absorption coefficients were determined from PSAP and PSAP3 $\lambda$ measurements using 30 -min averages. The measurement periods of PSAP and PSAP $3 \lambda$ were from January 2002 to July 2013 and from June 2006 to July 2013, respectively. The measurement wavelength was $565 \mathrm{~nm}$ for PSAP and 467, 530, and $660 \mathrm{~nm}$ for PSAP3 $\lambda$. The values measured by PSAP and PSAP3 $\lambda$ were corrected using Bond et al.'s (1999) method.

The integrating nephelometer is widely used for 
measuring aerosol scattering coefficients; however, it cannot measure light scattered in the extreme forward or backward directions (scattering angles near $0^{\circ}$ and $180^{\circ}$; Heintzenberg and Charlson 1996; Anderson et al. 1996; Anderson and Ogren 1998; Müller et al. 2009). To correct this truncation error, information on aerosol absorption properties and the particle size distribution is necessary (Bond et al. 2009). We used a recently developed method that uses multiwavelength scattering and absorption coefficient data to calculate corrected scattering coefficients (see Section 3) (Uchiyama 2014) and obtained more accurate values for scattering coefficients and other single scattering properties (extinction coefficients, SSA, and asymmetry factor). To analyze single-wavelength PSAP data, together with three-wavelength PSAP3 $\lambda$ data, absorption coefficients were extrapolated by assuming wavelength dependence $\lambda^{-\alpha}$. In this study, $\alpha=1.02$ $( \pm 0.16$ ), the average value of monthly average (standard deviation) from March 2006 to July 2013, was used.

The continuous measurements were performed at observation building for surface radiation measurements at MRI $\left(36.06^{\circ} \mathrm{N}, 140.01^{\circ} \mathrm{E}\right)$ in Tsukuba, Japan. Tsukuba is approximately $60 \mathrm{~km}$ northeast of the center of Tokyo and has a population of about 200,000 with a population density of about 750 people $\mathrm{km}^{-2}$. Regional land is used for vegetable and rice fields, except in the central city area. There is no large source of anthropogenic emissions near the observation site.

Sample air was drawn into the building through an intake $3 \mathrm{~m}$ above the ground by using a stainless steel tube with an inner diameter of $20 \mathrm{~mm}$. Room temperature was controlled by weak air conditioning. Therefore, it was slightly cooler (higher) than the outside air temperature in summer (winter), and was almost the same as the outside air temperature in spring and autumn. The air was heated to $50^{\circ} \mathrm{C}-60^{\circ} \mathrm{C}$ near the entrance of the intake. Inside the building, the air was divided and introduced into each instrument through conductive silicone tubes covered with heat insulating material. These steps ensured that the sample air met the necessary condition of low relative humidity.

\section{Methods}

\subsection{Data analysis}

The nephelometer data require corrections for the angular truncation error and the light source distribution error. Our correction used a statistical method to simultaneously retrieve the complex refraction index (both real and imaginary parts) and the aerosol size distribution from the three-wavelength scattering and hemispheric back-scattering coefficients and three-wavelength absorption coefficients (Uchiyama 2014). In this method, we seek the solution that minimizes the following function:

$$
\begin{aligned}
J(\mathbf{x})= & \frac{1}{2}\left(\mathbf{x}-\mathbf{x}_{0}\right)^{t} \mathbf{C}_{0}^{-1}\left(\mathbf{x}-\mathbf{x}_{0}\right) \\
& +\frac{1}{2}\left(\mathbf{f}(\mathbf{x})-\mathbf{f}_{o b s}\right)^{t} \mathbf{C}_{o b s}^{-1}\left(\mathbf{f}(\mathbf{x})-\mathbf{f}_{o b s}\right),
\end{aligned}
$$

where vector $\mathbf{x}$ is a parameter to be retrieved, vector $\mathbf{x}_{0}$ is the first estimate of the parameter, vector $\mathbf{f}_{o b s}$ is the measured data, $\mathbf{f}(\mathbf{x})$ is the measured value of $\mathbf{x}$, and $\mathbf{x}^{t}$ is the transpose of vector $\mathbf{x}$. It is assumed that the errors of vectors $\mathbf{x}_{0}$ and $\mathbf{f}_{o b s}$ are uncorrelated and follow the normal distribution of the covariance matrices $\mathbf{C}_{0}$ and $\mathbf{C}_{\text {obs }}$.

Once the complex refraction index and aerosol size distribution are retrieved, single scattering properties (extinction, scattering and absorption coefficients, SSA, phase function, and asymmetry factor) can be calculated. The resulting scattering coefficients are the corrected values. Results of a numerical simulation showed that the root mean square errors (RMSEs) of the SSA calculated directly from the measured values are $0.014-0.021$ and that of the SSA calculated from the corrected values is 0.002 , corresponding to a relative error of $0.2 \%$ (Uchiyama 2014).

\subsection{Calculation of trends}

Some aerosol properties displayed seasonal variation as well as long-term trends. We removed the seasonal variation by assuming the simple form of the following equation:

$$
\begin{aligned}
f(t)= & (a \cdot t+b) \cdot\left(c_{0}+c_{1} \sin (\omega t)+c_{2} \cos (\omega t)\right. \\
& \left.+c_{3} \sin (2 \omega t)+c_{4} \cos (2 \omega t)\right),
\end{aligned}
$$

where $\omega=2 \pi / T$ and $T=1$ year. In this equation, periods of 1 year and 0.5 year are taken into account, and the long-term trend is $a \cdot c_{0}$. The coefficients are determined by the following procedure. First, coefficients $a$ and $b$ are determined by the least squares method using all data. Second, coefficients $c_{0}, c_{1}$, $c_{2}, c_{3}$, and $c_{4}$ are determined from $f(t) /(a \cdot t+b)$ by the least squares method. This procedure is repeated several times to reduce the residual errors. Our analysis of the long-term trend used monthly average values. 
Table 1. Trends of aerosol properties.

\begin{tabular}{lcccc}
\hline & $1 \mathrm{WL}$ & $1 \mathrm{WL}$ & $1 \mathrm{WL}$ & $3 \mathrm{WL}$ \\
& $2002-2006$ & $2006-2013$ & $2002-2013$ & $2006-2013$ \\
\hline Cabs(467nm) & $\left(7.6 \times 10^{-7 *}\right)$ & $\left(-9.9 \times 10^{-7 *}\right)$ & $\left(-6.1 \times 10^{-7 *}\right)$ & $-6.4 \times 10^{-7 *}$ \\
Cabs(530nm) & $6.7 \times 10^{-7 *}$ & $-8.7 \times 10^{-7 *}$ & $-5.4 \times 10^{-7 *}$ & $-5.6 \times 10^{-7 *}$ \\
Cabs(660nm) & $\left(5.3 \times 10^{-7 *}\right)$ & $\left(-7.0 \times 10^{-7 *}\right)$ & $\left(-4.3 \times 10^{-7 *}\right)$ & $-4.7 \times 10^{-7 *}$ \\
\hline Alpha_abs & & & & $2.06 \times 10^{-2 *}$ \\
\hline Cext(450nm) & $-6.5 \times 10^{-6 *}$ & $-2.8 \times 10^{-6 *}$ & $-1.7 \times 10^{-6 *}$ & $-2.5 \times 10^{-6 * *}$ \\
Cext(550nm) & $-4.8 \times 10^{-6 *}$ & $-2.2 \times 10^{-6 *}$ & $-1.5 \times 10^{-6 *}$ & $-2.0 \times 10^{-6 * *}$ \\
Cext(700nm) & $-3.2 \times 10^{-6 *}$ & $-1.4 \times 10^{-6 *}$ & $-1.1 \times 10^{-6 *}$ & $-1.2 \times 10^{-6 * *}$ \\
\hline Csca(450nm) & $-7.3 \times 10^{-6 *}$ & $-1.8 \times 10^{-6}$ & $-9.7 \times 10^{-7}$ & $-1.9 \times 10^{-6}$ \\
Csca(550nm) & $-5.5 \times 10^{-6 *}$ & $-1.4 \times 10^{-6}$ & $-8.8 \times 10^{-7}$ & $-1.4 \times 10^{-6}$ \\
Csca(700nm) & $-3.8 \times 10^{-6 *}$ & $-7.7 \times 10^{-7}$ & $-6.6 \times 10^{-7 * *}$ & $-7.7 \times 10^{-7}$ \\
\hline SSA(450nm) & $-1.6 \times 10^{-2 *}$ & $8.6 \times 10^{-3 *}$ & $7.2 \times 10^{-3 *}$ & $6.0 \times 10^{-3 *}$ \\
SSA(550nm) & $-1.7 \times 10^{-2 *}$ & $9.3 \times 10^{-3 *}$ & $7.4 \times 10^{-3 *}$ & $6.9 \times 10^{-3 *}$ \\
SSA(700nm) & $-2.0 \times 10^{-2 *}$ & $1.1 \times 10^{-2 *}$ & $7.9 \times 10^{-3 *}$ & $8.8 \times 10^{-3 *}$ \\
\hline Asymmetry factor(450nm) & $1.4 \times 10^{-3}$ & $2.2 \times 10^{-3 *}$ & $0.4 \times 10^{-3}$ & $3.5 \times 10^{-3 *}$ \\
Asymmetry factor(550nm) & $1.8 \times 10^{-3}$ & $2.4 \times 10^{-3 *}$ & $0.2 \times 10^{-3}$ & $3.7 \times 10^{-3 *}$ \\
Asymmetry factor(700nm) & $2.6 \times 10^{-3}$ & $1.1 \times 10^{-3}$ & $-1.3 \times 10^{-3 * *}$ & $2.5 \times 10^{-3 * *}$ \\
\hline Alpha_ext & $-5.1 \times 10^{-3}$ & $3.5 \times 10^{-3}$ & $1.4 \times 10^{-2 *}$ & $-4.5 \times 10^{-3}$ \\
Alpha_sca & $7.9 \times 10^{-3}$ & $-3.5 \times 10^{-3}$ & $1.1 \times 10^{-2 *}$ & $-1.3 \times 10^{-2}$ \\
\hline Reff & $-1.2 \times 10^{-3}$ & $1.5 \times 10^{-3}$ & $-0.5 \times 10^{-3}$ & $3.6 \times 10^{-3 *}$ \\
Veff & $1.2 \times 10^{-1}$ & $-4.0 \times 10^{-2}$ & $-1.0 \times 10^{-1 *}$ & $6.1 \times 10^{-2}$ \\
\hline Asters(*)meanthat & & & & \\
\hline
\end{tabular}

Asterisk (*) means that the trend is significant at the $95 \%$ confidence level.

Two asterisks $(* *)$ mean that the trend is significant at the $90 \%$ confidence level.

$1 \mathrm{WL}$ means that one-wavelength PSAP was used as the data. $3 \mathrm{WL}$ means that three-wavelength PSAP3 $\lambda$ was used.

Cabs: absorption coefficient $\left(\mathrm{m}^{-1}\right)$, Alpha_abs: Ångström exponent for Cabs, Cext: extinction coefficient $\left(\mathrm{m}^{-1}\right)$, Csca: scattering coefficient $\left(\mathrm{m}^{-1}\right), \overline{\mathrm{SSA}}$ : single scattering albedo, Alpha_ext: Ångström exponent for Cext, Alpha_sca: Ångström exponent for Csca, Reff: effective radius ( $\mu \mathrm{m})$, Veff: effective variance.

\section{Results}

\subsection{Trends of aerosol properties}

The trends of aerosol properties are summarized in Table 1. The time series of scattering coefficients at a wavelength of $550 \mathrm{~nm}$ and absorption coefficients at $530 \mathrm{~nm}$ are shown in Fig. 1. The absorption coefficients were fitted well by Eq. (2) in contrast to the scattering coefficients, which did not (figures not shown). The absorption coefficients showed a clear seasonal variation, but the scattering coefficients did not. The absorption coefficients were large in the late autumn and early winter and small in the summer. The trends of scattering coefficients from 2002 to 2013 were $-9.7 \times 10^{-7},-8.8 \times 10^{-7}$, and $-6.6 \times 10^{-7}$ $\mathrm{m}^{-1}$ year $^{-1}$ at wavelengths of 450,550 , and $700 \mathrm{~nm}$, respectively. The trend of absorption coefficients from
2002 to 2013 was $-5.4 \times 10^{-7} \mathrm{~m}^{-1}$ year $^{-1}$ at $530 \mathrm{~nm}$, and those from 2006 to 2013 were $-6.4 \times 10^{-7},-5.6 \times$ $10^{-7}$, and $-4.7 \times 10^{-7} \mathrm{~m}^{-1}$ year $^{-1}$ at 467,530 , and 660 $\mathrm{nm}$, respectively. Both scattering and absorption coefficients showed a decreasing trend, but only the trend of the absorption coefficients was significant at the 95 $\%$ confidence level. A similar decrease in the absorption coefficients was found by a radiometer data analysis (Kudo et al. 2010, 2012).

The extinction coefficients, which are the summation of scattering and absorption coefficients, showed decreasing trends of $-1.7 \times 10^{-6},-1.5 \times 10^{-6}$, and -1.1 $\times 10^{-6} \mathrm{~m}^{-1}$ year $^{-1}$ at wavelengths of 450,550 , and 700 $\mathrm{nm}$, respectively, from 2002 to 2013 . Extinction coefficients from 2006 to 2013 were $-2.5 \times 10^{-6},-2.0 \times$ $10^{-6}$, and $-1.2 \times 10^{-6}$ year $^{-1}$ at 450,550 , and $700 \mathrm{~nm}$, respectively. The trend was significant at the $95 \%$ 


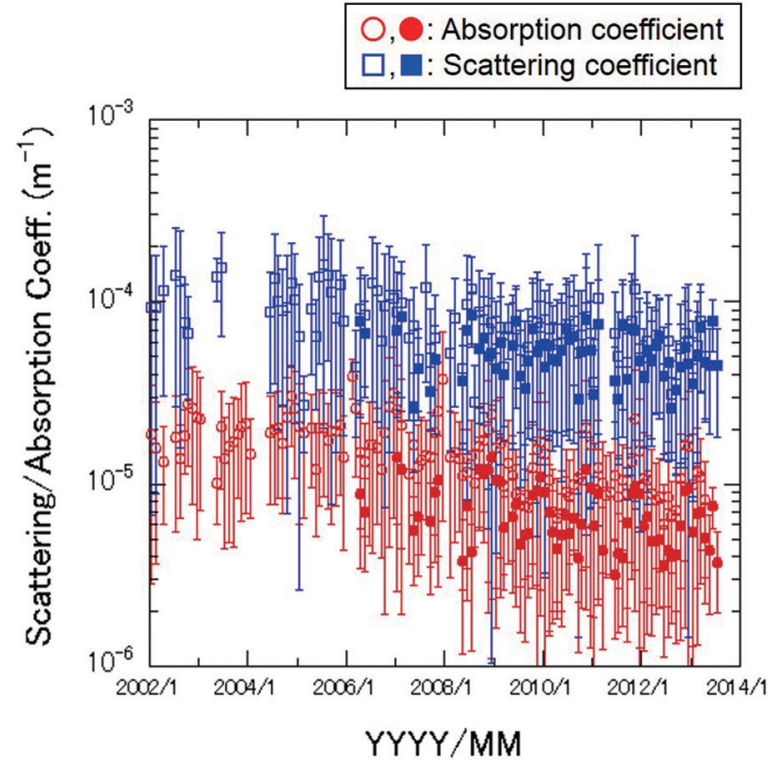

Fig. 1. Monthly average absorption coefficient $(\circ, \bullet)$ at $530 \mathrm{~nm}$ and monthly average scattering coefficient $(\square, \boldsymbol{\square})$ at $550 \mathrm{~nm}$ in the period from 2002 to 2013. Data are monthly average and vertical bar indicates standard deviation. Open circle $(\circ)$ indicates absorption coefficient measured by one-wavelength PSAP and closed circle $(\bullet)$ indicates that measured by three-wavelength PSAP3 $\lambda$. Scattering coefficient was retrieved one. Open square ( $\square$ ) is retrieved using data of one-wavelength PSAP and TSI 3563 nephelometer. Close square ( $\mathbf{\square})$ is retrieved using data of three-wavelength PSAP3 $\lambda$ and TSI 3563 nephelometer.

confidence level during 2002-2013 and significant at the $90 \%$ confidence level during 2006-2013.

The time series of the SSA at $550 \mathrm{~nm}$ is shown in Fig. 2. Most SSA values lie between 0.8 and 0.9. In a clear pattern of seasonal variation, the SSA was large (relative absorption is less) in spring and early summer and small in late autumn and early winter. Trends of the SSA from 2002 to 2013 were $7.2 \times 10^{-3}$, $7.4 \times 10^{-3}$, and $7.9 \times 10^{-3}$ year $^{-1}$ at 450,550 , and 700 $\mathrm{nm}$, respectively, and those from 2006 to 2013 were $6.0 \times 10^{-3}, 6.9 \times 10^{-3}$, and $8.8 \times 10^{-3}$ year $^{-1}$. These trends were significant at the $95 \%$ confidence level. The seasonal variation in the SSA was also apparent in the radiometer data (Nishizawa et al. 2004; Kudo et al. 2010), as was the increase in the SSA (Kudo et al. 2010, 2012).

If the decreasing trends of extinction coefficients and the increasing trends of the SSA occur in the

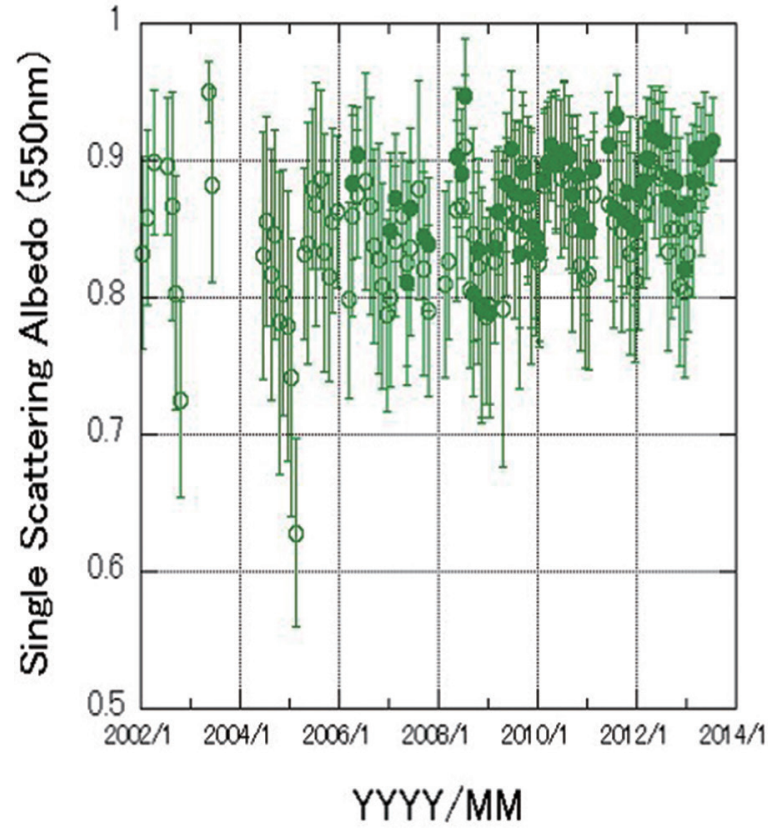

Fig. 2. Same as Fig. 1, except SSA at $550 \mathrm{~nm}$.

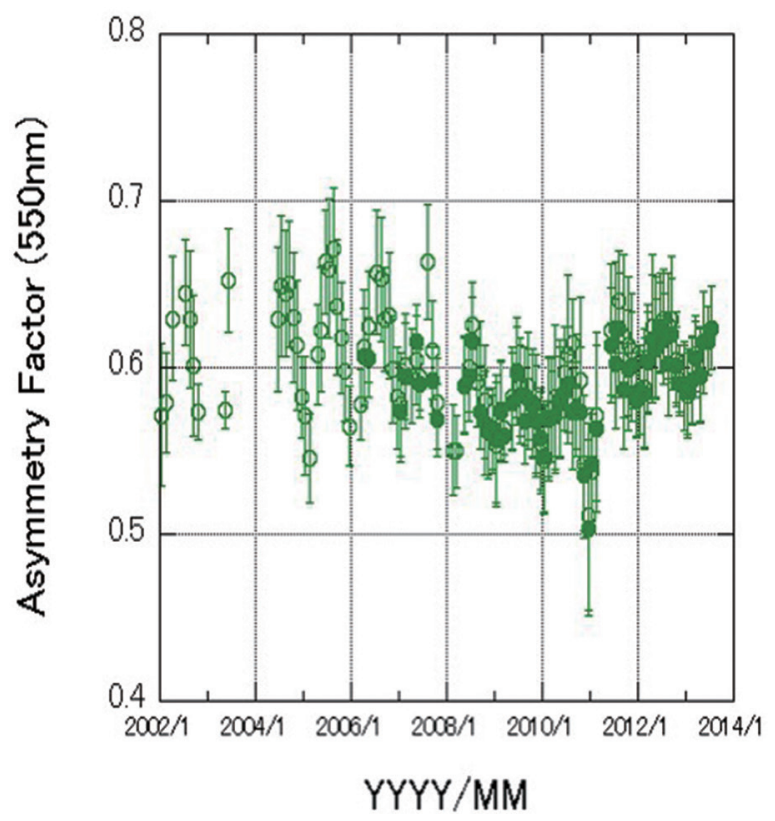

Fig. 3. Same as Fig. 1, except for the asymmetry factor.

whole atmosphere, these trends cause an increase in the downward solar irradiance at the Earth's surface (Kudo et al. 2010).

Asymmetry factor is defined as follows (Liou 2002): 


$$
g=\frac{1}{2} \int_{-1}^{1} P(\cos \Theta) \cos \Theta d \cos \Theta,
$$

where $P(\cos \Theta)$ is the phase function of scattering, and $\Theta$ is the scattering angle. Asymmetry factor varies between 1 and -1 , is 0 for isotropic scattering, and can usefully characterize the shape of the phase function of scattering.

The time series of asymmetry factor at $550 \mathrm{~nm}$ is shown in Fig. 3. The values of asymmetry factor varied between 0.5 and 0.65 and displayed a clear seasonal variation, being large in summer and small in late autumn and early winter. The trends of asymmetry factor from 2002 to 2013 were $0.4 \times 10^{-3}, 0.2 \times$ $10^{-3}$, and $-1.3 \times 10^{-3}$ year $^{-1}$ at 450,550 , and $700 \mathrm{~nm}$, respectively, and those from 2006 to 2013 were 3.5 $\times 10^{-3}, 3.7 \times 10^{-3}$, and $2.5 \times 10^{-3}$ year $^{-1}$. The trends from 2002 to 2013 were not significant at the $95 \%$ confidence level, whereas those from 2006 to 2013 were significant at the $90 \%$ or $95 \%$ confidence level, depending on wavelength. Asymmetry factors from 2008 to 2010 were a little smaller than those in the other periods, which may affect the increasing trends for 2006-2013. A lower asymmetry factor means that the relative contribution of smaller particles to the size distribution is greater. Because the measurement procedure did not change between 2006 and 2013, this change in the particle size distribution can be regarded as real. The trends at $700 \mathrm{~nm}$ for both 2002 2006 and 2006-2013 were positive (increasing), but the trend at $700 \mathrm{~nm}$ for 2002-2013 was negative (decreasing). Though the time series of asymmetry factor at $700 \mathrm{~nm}$ is not shown here, this decreasing trend was caused by the lower asymmetry factor from 2011 to 2013 than from 2002 to 2006. This tendency can be seen in Fig. 3.

The wavelength dependence of the extinction coefficients is approximated as follows:

$$
C_{\text {ext }} \propto \lambda^{-\alpha} \text {. }
$$

The exponent $\alpha$ called the extinction Ångström exponent, is an index of the size distribution; when $\alpha$ is large, the size distribution favors small particles, and when $\alpha$ is small, the size distribution favors large particles.

The time series of extinction Ångström exponents is shown in Fig. 4. The value varied mostly between 1.3 and 1.8 and did not show seasonal variation. When airborne mineral dust is abundant over the observation site, the extinction Ångström exponent becomes less than 0.5 for a day or so. However, monthly average values are not affected by dust events due to the short duration of dust event. The trend of extinction Ångström exponent was $1.4 \times$ $10^{-2}$ year $^{-1}$ from 2002 to 2013 and $-4.5 \times 10^{-3}$ year $^{-1}$ from 2006 to 2013. The trend from 2002 to 2013 was significant at the $95 \%$ confidence level. After the summer of 2012, periods of lower extinction Ångström exponent were much more common. This accounts for the decreasing tendency from 2006 to 2013. Usually, an increase in the extinction Angström exponent means an increase in smaller particles, which should correspond to a decrease in the asymmetry factor. The trends in asymmetry factor and extinction Ångström exponent were consistent from 2006 to 2013, but for 2002 to 2013, this relationship was not clear.

We can analogously define an Ångström exponent for absorption coefficients to the extinction Ångström exponent as follows:

$$
C_{a b s} \propto \lambda^{-\alpha} \text {. }
$$

The time series of absorption Ångström exponents is shown in Fig. 5. The value varied mostly between 0.8 and 1.2 and displayed clear seasonal variation. The trend of the absorption Ångström exponent from 2006 to 2012 was $2.1 \times 10^{-2}$ year $^{-1}$ and was significant at the $95 \%$ confidence level. The values in 2008 and 2009 ranged from 0.8 to 1 and were lower than those in other years.

The absorption Ångström exponent depends on the source of emission, aerosol composition, and the stage of aerosol aging (Kirchstetter et al. 2004; Bergstrom et al. 2007; Lewis et al. 2008; Yang et al. 2009; Russell et al. 2010). Light absorption by motor vehicle aerosols exhibits a relatively weak wavelength dependence; the absorption Ångström exponent is approximately 1 , indicating that black carbon is the dominant absorbing aerosol component. Biomass smoke aerosols from biomass burning have much stronger wavelength dependence, with absorption Ångström exponents of approximately 1.5 to 2.5 , as a result of enhanced light absorption at wavelengths shorter than $600 \mathrm{~nm}$ due to the organic carbon component. Mineral dust aerosol also has stronger wavelength dependence, with absorption Ångström exponents of approximately 1.5 to 3.0.

In our data, the absorption Ångström exponent tended to increase. As lower absorption Ångström exponents are attributable to motor vehicles, the restriction of diesel engines in the Tokyo area since 2003 may have caused a decrease in aerosols with lower absorption Ångström exponents; thus, the 


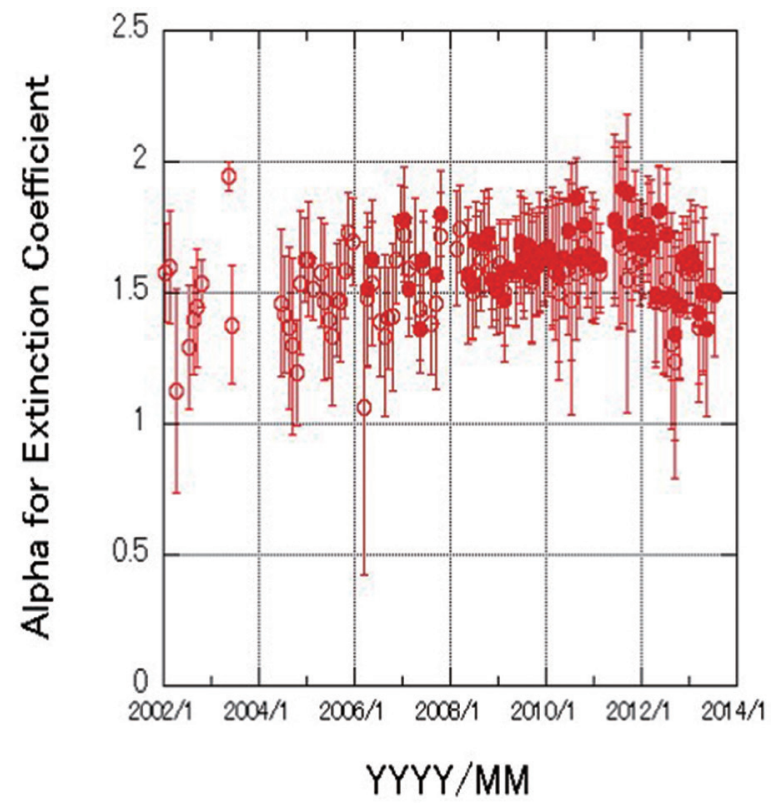

Fig. 4. Same as Fig. 1, except for the Ångström exponent for extinction coefficient.

relative contribution of aerosols with higher absorption Ångström exponents may have increased. The average value of the absorption Ångström exponent from 2006 to 2012 was about 1.02 . The values in 2008 and 2009 were 0.8 to 1 . It is possible that a local source near the observation site produced aerosols with characteristics different from those of the typical aerosol during these years.

Figure 5 shows a clear seasonal variation in the absorption Ångström exponent, which was small in summer (about 1) and large in late autumn and early winter (about 1.15). This may reflect seasonal local biomass burning in the late autumn and early winter.

The effective radius and variance are defined as follows (Hansen and Travis 1974):

$$
r_{e f f}=\frac{\int_{r_{1}}^{r_{2}} r \pi r^{2} n(r) d r}{\int_{r_{1}}^{r_{2}} \pi r^{2} n(r) d r},
$$

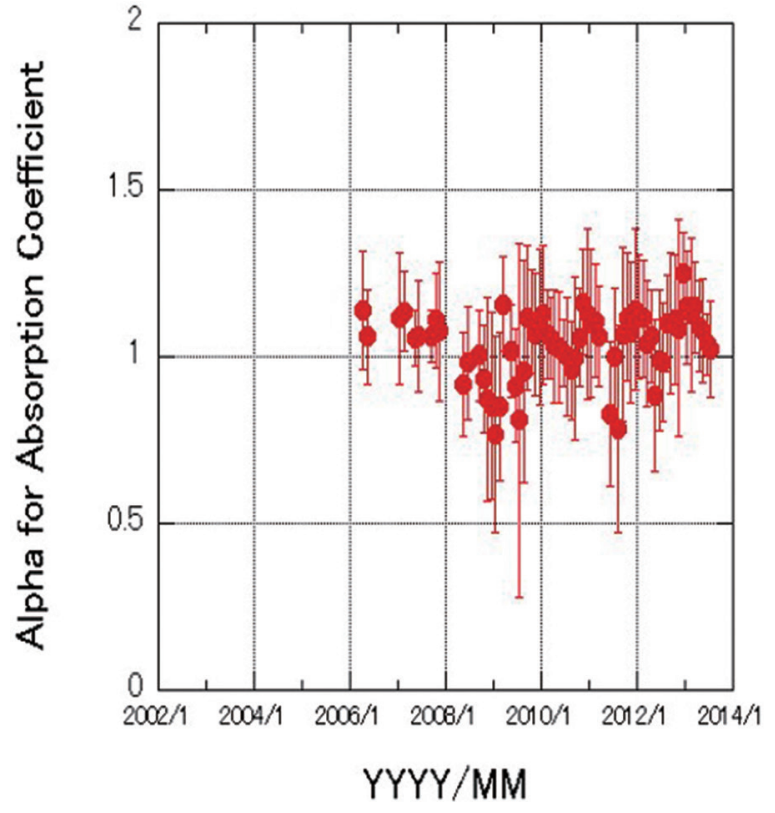

Fig. 5. Same as Fig. 1, except for the Ångström exponent for absorption coefficient.

$$
v_{e f f}=\frac{\int_{r_{1}}^{r_{2}}\left(r-r_{e f f}\right)^{2} \pi r^{2} n(r) d r}{r_{e f f}^{2} \int_{r_{1}}^{r_{2}} \pi r^{2} n(r) d r} .
$$

The time series of effective radius $\left(r_{e f f}\right)$ is shown in Fig. 6. The values of monthly average $r_{\text {eff }}$ varied between 0.08 and 0.2 , tending to be larger (with larger standard deviations) in summer and smaller in winter (with smaller standard deviations), except for the summers of 2008 and 2009. The trend of $r_{\text {eff }}$ from 2002 to 2013 was $-0.5 \times 10^{-3} \mu \mathrm{m}$ year $^{-1}$ (not significant at the $95 \%$ confidence level) and that from 2006 to 2013 was $3.6 \times 10^{-3} \mu \mathrm{m} \mathrm{year}^{-1}$ (significant at the $95 \%$ confidence level). After the summer of 2012, periods of larger effective radius were much more common. This accounts for the increasing tendency from 2006 to 2013. Excluding these period data, the tendency was negative (decreasing). The tendencies of asymmetry factor, extinction Ångström exponent and effective radius for 2006 to 2013 were consistent; these tendencies correspond to an increase in larger particles. However, the tendencies of these parameters for 2002 to 2013 were not clear. 


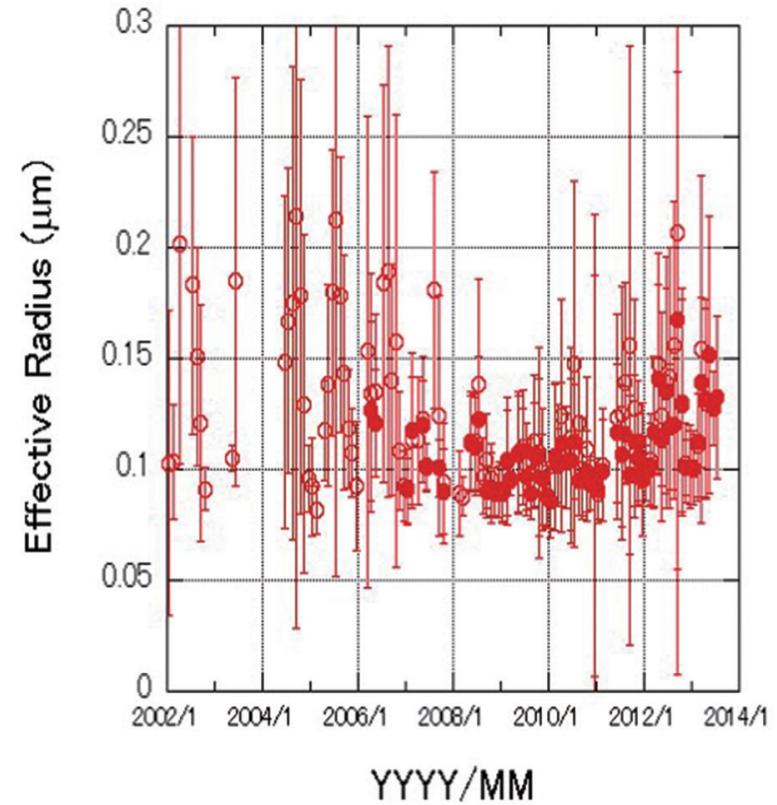

Fig. 6. Same as Fig. 1, except for the effective radius.

The time series of effective variance $\left(v_{e f f}\right)$ is shown in Fig. 7. The values of monthly average $v_{\text {eff }}$ varied between 2 and 6 , with a large scatter and standard deviations of about 2 . The trend of $v_{\text {eff from } 2002 \text { to }}$ 2013 was $-1.0 \times 10^{-1}$ year $^{-1}$ and that from 2006 to 2013 was $6.1 \times 10^{-2}$ year $^{-1}$. The 2002-2013 trend was significant at the $95 \%$ confidence level.

\subsection{Climatology}

This section presents the frequency distribution of aerosol optical properties (extinction coefficient at $550 \mathrm{~nm}$, absorption coefficients at $530 \mathrm{~nm}$, SSA at $550 \mathrm{~nm}$, and asymmetry factor at $550 \mathrm{~nm}$ ) based on the data for 2006-2013. For the period 2006-2013, we used three-wavelength PSAP $3 \lambda$ data. This section also presents optical properties classified by the magnitude of extinction Ångström exponent.

\section{a. Frequency distribution}

The frequency distribution of extinction coefficients using all data is shown in Fig. 8a, and a seasonal breakdown is shown in Fig. 8b. The most frequent value was $25 \times 10^{-6} \mathrm{~m}^{-1}$, and most of the data were below $200 \times 10^{-6} \mathrm{~m}^{-1}$. The most frequent values in spring (March to May) and summer (June to August) were largest at $35 \times 10^{-6} \mathrm{~m}^{-1}$, the value in autumn (September to November) was $25 \times 10^{-6}$ $\mathrm{m}^{-1}$, and that in winter (December to February) was

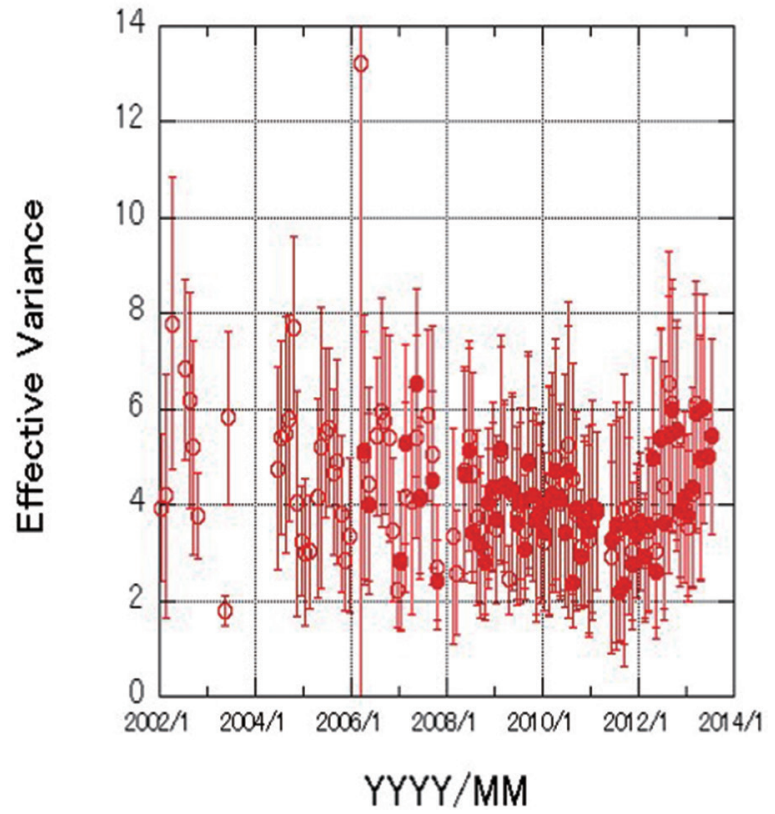

Fig. 7. Same as Fig. 1, except for the effective variance.

smallest at $15 \times 10^{-6} \mathrm{~m}^{-1}$. In winter, the smaller extinction coefficients were observed when cold air masses flowed from Siberia to Japan. Values greater than $150 \times 10^{-6} \mathrm{~m}^{-1}$ were more frequent in winter and autumn than in spring and summer. Night-time temperature inversions in winter and late autumn tend to accumulate aerosols and increase extinction coefficients. The monthly average values of some aerosol properties are shown in Table 2. The monthly average values of the extinction and absorption coefficients in Table 2 show the same characteristics as those shown in Fig. 8.

The frequency distribution of absorption coefficients is shown in Fig. 9. The most frequent value in all seasons was $3.0 \times 10^{-6} \mathrm{~m}^{-1}$, and most of the data were below $30 \times 10^{-6} \mathrm{~m}^{-1}$. The frequency of absorption coefficients greater than $15 \times 10^{-6} \mathrm{~m}^{-1}$ was higher in autumn and winter than in spring and summer. Inversion layers have the same effect on absorption coefficients as they do on extinction coefficients. The most frequent value does not depend on the season. This suggests that most of the absorbing aerosols are emitted from the area near the observation site.

The frequency distribution of the SSA is shown in Fig. 10. The most frequent value in the entire data was near 0.905 . The most frequent SSA values in spring, summer, autumn, and winter were 0.925, 0.925, 0.885 , and 0.875 , respectively. The seasonal effect in 


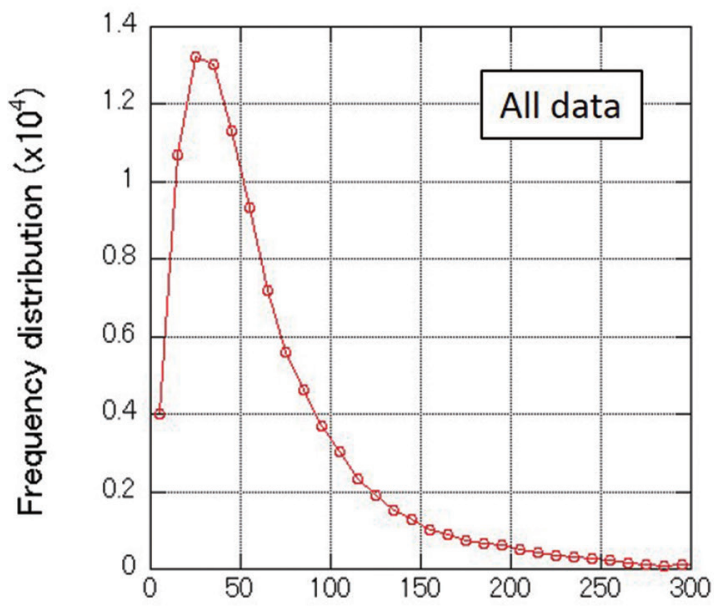

Extinction Goefficient $(550 \mathrm{~nm})\left(\times 10^{-6}\right)\left(\mathrm{m}^{-1}\right)$

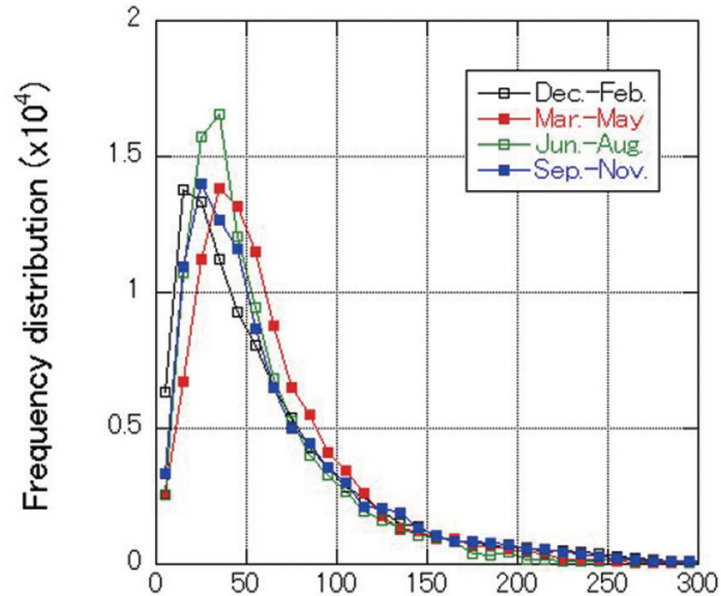

Extinction Goefficient $(550 \mathrm{~nm})\left(\times 10^{-6}\right)\left(\mathrm{m}^{-1}\right)$

Fig. 8. Frequency distribution of extinction coefficient. Data in the period from 2006 to 2013 were used. (a) Frequency distribution of extinction coefficient for entire data. (b) Frequency distribution of extinction coefficient for each season: spring (March to May), summer (June to August), autumn (September to November), and winter (December to February).

Table 2. Monthly averages of aerosol properties.

\begin{tabular}{|c|c|c|c|c|c|c|c|c|c|c|c|c|}
\hline Month & 1 & 2 & 3 & 4 & 5 & 6 & 7 & 8 & 9 & 10 & 11 & 12 \\
\hline $\begin{array}{l}\text { Cabs } \\
\text { SG }\end{array}$ & $\begin{array}{c}8.34 \\
(7.52)\end{array}$ & $\begin{array}{c}8.43 \\
(6.69)\end{array}$ & $\begin{array}{c}6.00 \\
(4.05)\end{array}$ & $\begin{array}{c}5.84 \\
(3.82)\end{array}$ & $\begin{array}{c}5.69 \\
(3.62)\end{array}$ & $\begin{array}{c}5.96 \\
(4.30)\end{array}$ & $\begin{array}{r}4 . \\
(2 . \\
\end{array}$ & $\begin{array}{c}4.69 \\
(3.00)\end{array}$ & $\begin{array}{c}5.72 \\
(4.05)\end{array}$ & $\begin{array}{c}8.51 \\
(5.85)\end{array}$ & $\begin{array}{l}11.21 \\
(9.21)\end{array}$ & $\begin{array}{c}11.20 \\
(10.12)\end{array}$ \\
\hline $\begin{array}{l}\text { Alpha_abs } \\
\text { SG }\end{array}$ & 1. & $\begin{array}{r}1 . \\
(0 .\end{array}$ & $\begin{array}{l}1 . \\
(0 .\end{array}$ & $\begin{array}{l}1.0 \\
(0.1\end{array}$ & & $\begin{array}{l}0 . \\
(0 .\end{array}$ & & $\begin{array}{l}1.0 \\
(0.2\end{array}$ & $\begin{array}{l}1 . \\
(0.2\end{array}$ & $\begin{array}{l}1 . \\
(0 .\end{array}$ & 1. & $\begin{array}{c}1.11 \\
(0.25)\end{array}$ \\
\hline $\begin{array}{l}\text { Cext }(550 \mathrm{~nm}) \times 10^{-6} \\
\text { SG }\end{array}$ & $\begin{array}{c}51.99 \\
(40.83)\end{array}$ & $\begin{array}{c}71.47 \\
(53.95)\end{array}$ & $\begin{array}{c}65.81 \\
(43.35)\end{array}$ & 37.52) & $\begin{array}{c}62.51 \\
(41.33) \\
\end{array}$ & $\begin{array}{c}69.42 \\
(53.02)\end{array}$ & $\begin{array}{c}48.03 \\
(31.23)\end{array}$ & $\begin{array}{c}40.38 \\
(28.33)\end{array}$ & $\begin{array}{c}47.28 \\
(31.97)\end{array}$ & $\begin{array}{c}70.19 \\
(49.54)\end{array}$ & $\begin{array}{c}75.23 \\
(63.66) \\
\end{array}$ & $\begin{array}{c}65.72 \\
(56.91)\end{array}$ \\
\hline $\begin{array}{l}\text { Csca }(550 \mathrm{~nm}) \times 10^{-6} \\
\text { SG }\end{array}$ & $\begin{array}{c}43.77 \\
(34.84)\end{array}$ & $\begin{array}{c}62.91 \\
(48.39) \\
\end{array}$ & $\begin{array}{c}59.62 \\
(40.06)\end{array}$ & $\begin{array}{c}55.76 \\
(34.44) \\
\end{array}$ & $\begin{array}{c}56.85 \\
(38.71) \\
\end{array}$ & $\begin{array}{c}63.62 \\
(50.39)\end{array}$ & $\begin{array}{r}43 . \\
(29 .\end{array}$ & $\begin{array}{c}35.29 \\
(25.84)\end{array}$ & $\begin{array}{l}41.40 \\
(28.87) \\
\end{array}$ & $\begin{array}{c}61.50 \\
(44.63) \\
\end{array}$ & $\begin{array}{c}64.20 \\
(56.07) \\
\end{array}$ & $\begin{array}{c}54.37 \\
(47.66) \\
\end{array}$ \\
\hline $\begin{array}{l}\mathrm{SSA}(550 \mathrm{~nm}) \\
\mathrm{SG}\end{array}$ & $\begin{array}{c}0.844 \\
(0.067)\end{array}$ & $\begin{array}{c}0.877 \\
(0.053)\end{array}$ & $\begin{array}{c}0.901 \\
(0.041)\end{array}$ & $\begin{array}{c}0.904 \\
(0.042)\end{array}$ & $\begin{array}{c}0.901 \\
(0.045)\end{array}$ & $\begin{array}{c}0.906 \\
(0.044)\end{array}$ & $\begin{array}{c}0.890 \\
(0.056)\end{array}$ & $\begin{array}{c}0.870 \\
(0.065)\end{array}$ & $\begin{array}{c}0.873 \\
(0.058)\end{array}$ & $\begin{array}{c}0.870 \\
(0.055)\end{array}$ & $\begin{array}{c}0.844 \\
(0.073)\end{array}$ & $\begin{array}{c}0.831 \\
(0.063)\end{array}$ \\
\hline $\begin{array}{l}\text { Asym.factor }(550 \mathrm{~nm}) \\
\text { SG }\end{array}$ & $\begin{array}{c}0.564 \\
(0.036)\end{array}$ & $\begin{array}{c}0.581 \\
(0.034)\end{array}$ & $\begin{array}{c}0.593 \\
(0.032)\end{array}$ & $\begin{array}{c}0.596 \\
(0.038)\end{array}$ & $\begin{array}{c}0.598 \\
(0.034)\end{array}$ & $\begin{array}{c}0.607 \\
(0.032)\end{array}$ & $\begin{array}{c}0.607 \\
(0.034)\end{array}$ & $\begin{array}{c}0.589 \\
(0.036)\end{array}$ & $\begin{array}{c}0.591 \\
(0.035)\end{array}$ & $\begin{array}{c}0.583 \\
(0.034)\end{array}$ & $\begin{array}{c}0.571 \\
(0.037)\end{array}$ & $\begin{array}{c}0.560 \\
(0.042)\end{array}$ \\
\hline $\begin{array}{l}\text { Alpha_ext } \\
\text { SG }\end{array}$ & $\begin{array}{c}1.66 \\
(0.21)\end{array}$ & $\begin{array}{c}1.62 \\
(0.24)\end{array}$ & $\begin{array}{l}1.59 \\
(0.26)\end{array}$ & $\begin{array}{l}1.53 \\
(0.29)\end{array}$ & $\begin{array}{l}1.60 \\
(0.27)\end{array}$ & $\begin{array}{c}1.59 \\
(0.24)\end{array}$ & $\begin{array}{l}1.67 \\
(0.30)\end{array}$ & $\begin{array}{c}1.62 \\
(0.29)\end{array}$ & $\begin{array}{c}1.59 \\
(0.33)\end{array}$ & $\begin{array}{l}1.68 \\
(0.21)\end{array}$ & $\begin{array}{l}1.65 \\
(0.19)\end{array}$ & $\begin{array}{c}1.62 \\
(0.19)\end{array}$ \\
\hline $\begin{array}{l}\text { Reff } \\
\text { SG }\end{array}$ & $\begin{array}{c}0.093 \\
(0.015)\end{array}$ & $\begin{array}{c}0.107 \\
(0.027)\end{array}$ & $\begin{array}{c}0.118 \\
(0.033)\end{array}$ & $\begin{array}{c}0.130 \\
(0.047)\end{array}$ & $\begin{array}{c}0.118 \\
(0.034)\end{array}$ & $\begin{array}{c}0.123 \\
(0.049)\end{array}$ & $\begin{array}{c}0.114 \\
(0.031)\end{array}$ & $\begin{array}{c}0.106 \\
(0.027)\end{array}$ & $\begin{array}{c}0.113 \\
(0.049)\end{array}$ & $\begin{array}{c}0.105 \\
(0.029)\end{array}$ & $\begin{array}{c}0.097 \\
(0.016)\end{array}$ & $\begin{array}{c}0.094 \\
(0.028)\end{array}$ \\
\hline $\begin{array}{l}\text { Veff } \\
\text { SG }\end{array}$ & $\begin{array}{c}3.52 \\
(1.67)\end{array}$ & $\begin{array}{c}4.13 \\
(2.17)\end{array}$ & $\begin{array}{c}4.50 \\
(2.25)\end{array}$ & $\begin{array}{c}4.82 \\
(2.41)\end{array}$ & $\begin{array}{c}4.29 \\
(2.25)\end{array}$ & $\begin{array}{c}4.61 \\
(2.15)\end{array}$ & $\begin{array}{c}3.98 \\
(2.31)\end{array}$ & $\begin{array}{c}4.11 \\
(2.53)\end{array}$ & $\begin{array}{c}4.43 \\
(2.52)\end{array}$ & $\begin{array}{c}3.58 \\
(1.80)\end{array}$ & $\begin{array}{c}3.57 \\
(1.65)\end{array}$ & $\begin{array}{c}3.79 \\
(1.80)\end{array}$ \\
\hline
\end{tabular}

Cabs $(530 \mathrm{~nm})$ : absorption coefficient at $530 \mathrm{~nm}\left(\mathrm{~m}^{-1}\right)$, SD: standard deviation, Alpha_abs: Ångström exponent for Cabs, $\operatorname{Cext}(550 \mathrm{~nm})$ : extinction coefficient at $550 \mathrm{~nm}\left(\mathrm{~m}^{-1}\right), \operatorname{Csca}(550 \mathrm{~nm})$ : scattering coefficient at $550 \mathrm{~nm}\left(\mathrm{~m}^{-1}\right), \operatorname{SSA}(550 \mathrm{~nm})$ : single scattering albedo at $550 \mathrm{~nm}$, Asym.factor $(550 \mathrm{~nm})$ : Asymmetry factor at $550 \mathrm{~nm}$, Alpha_ext: Ångström exponent for Cext, Reff: effective radius $(\mu \mathrm{m})$, Veff: effective variance. 


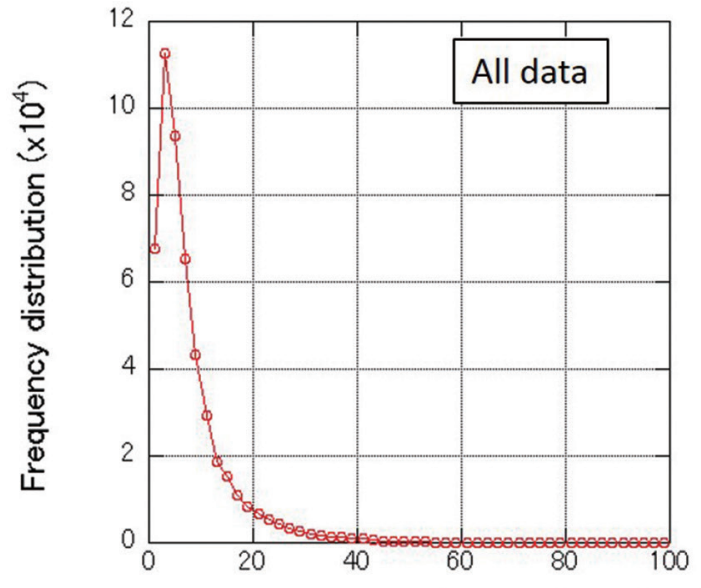

Absorption Coefficient $(550 \mathrm{~nm})\left(\times 10^{-6}\right)\left(\mathrm{m}^{-1}\right)$

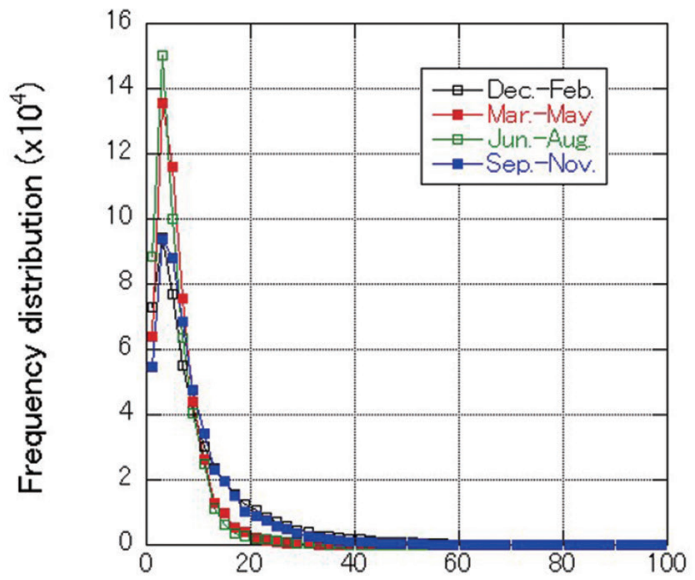

Absorption Goefficient $(550 \mathrm{~nm})\left(\times 10^{-6}\right)\left(\mathrm{m}^{-1}\right)$

Fig. 9. Same as Fig. 8, except for the absorption coefficient at $530 \mathrm{~nm}$.
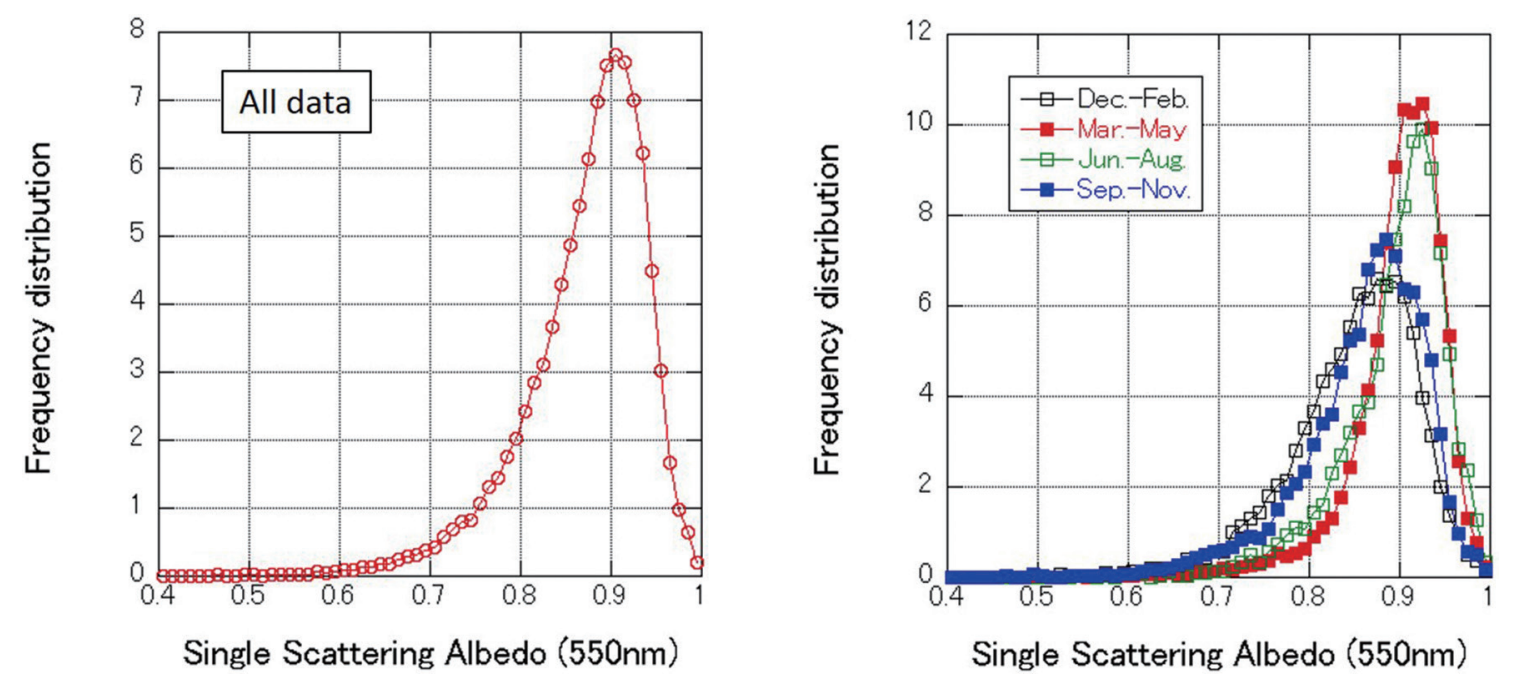

Fig. 10. Same as Fig. 8, except for SSA at $550 \mathrm{~nm}$.

late autumn and early winter reflects the burning of field biomass and fallen leaves near the observation site and the increased combustion of heating oil and gas in winter. The monthly average values of the SSA in Table 2 show the same features.

The frequency distribution of the asymmetry factor is shown in Fig. 11. The most frequent value in the entire data was 0.585 . The asymmetry factor was smaller in winter and autumn, highest in summer, and intermediate in spring. The marine air mass prevalent in summer increases the proportion of larger particles such as sea salt particles. Furthermore, the relative humidity in summer is higher than that in the other seasons, such that hygroscopic growth affects particle sizes. The sample air in spring includes more mineral dust from deserts in continental Asia than in autumn and winter. Therefore, the asymmetry factor is generally larger in spring than in autumn and winter.

From the above results on frequency distribution of aerosol properties, the variations in aerosol properties measured on the ground-based observation site were determined by the difference of synoptic scale 

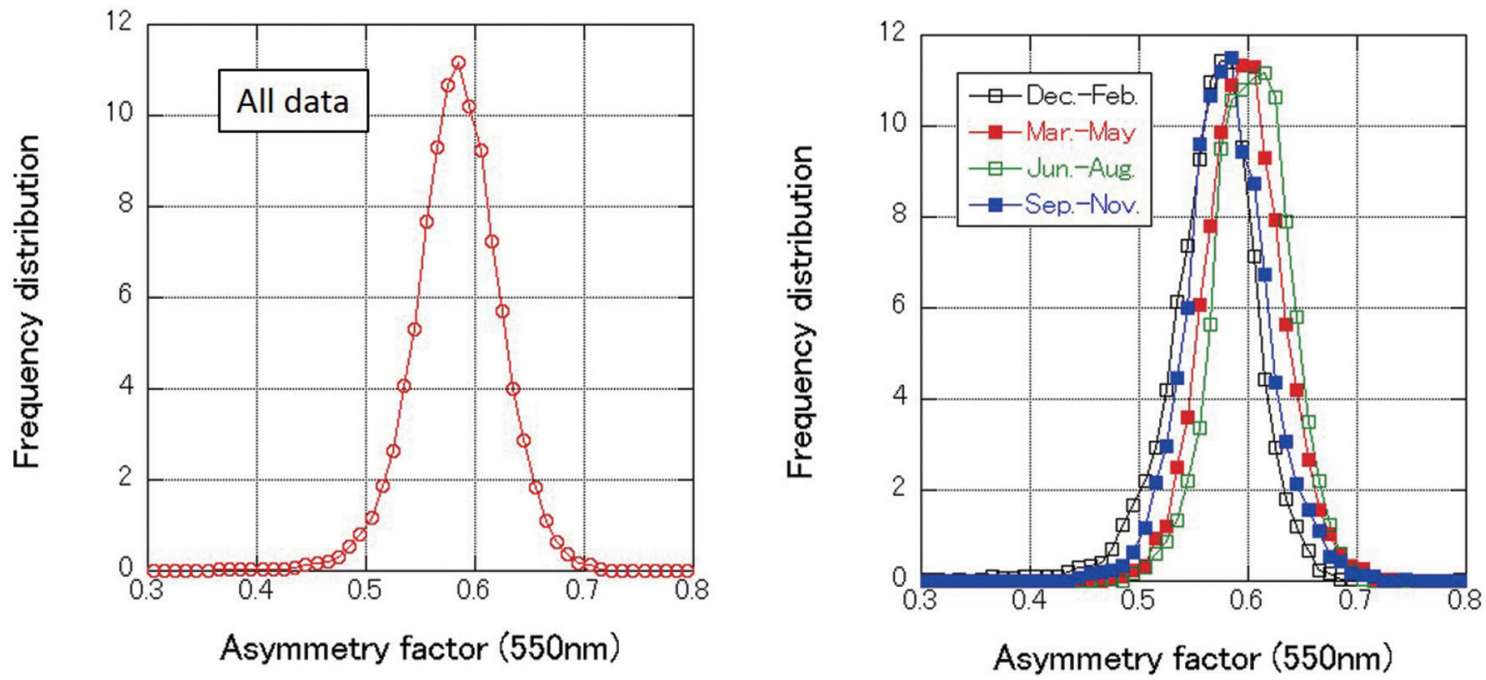

Fig. 11. Same as Fig. 8, except for asymmetry factor at $550 \mathrm{~nm}$.

(a)

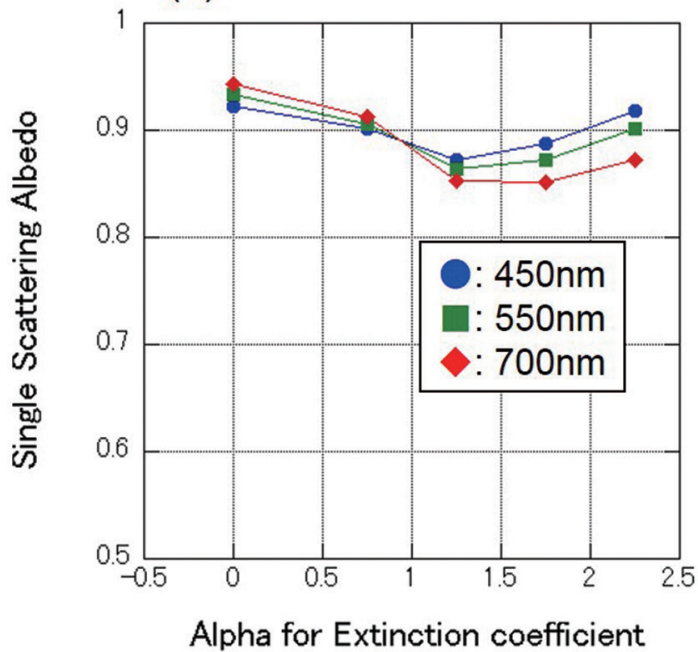

(b)

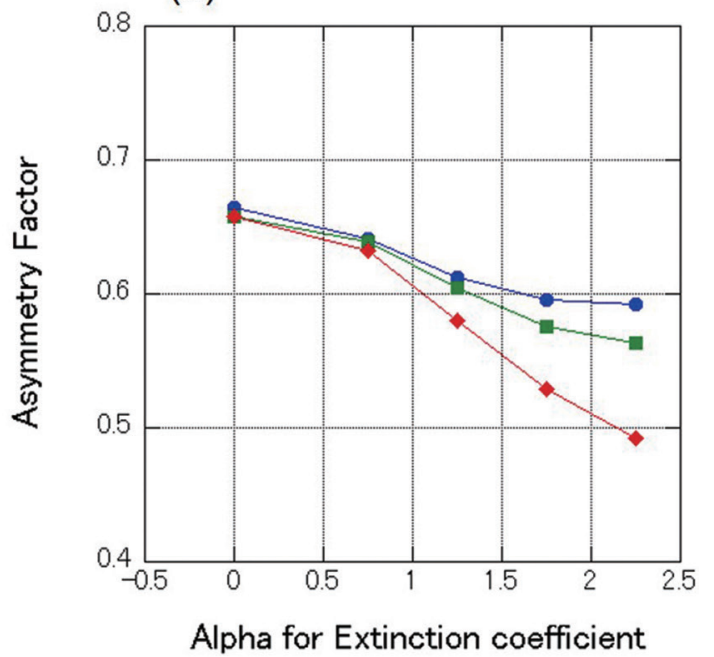

Fig. 12. (a) Relation between extinction Ångström exponent and SSA. (b) Relation between extinction Ångström exponent and asymmetry factor. Blue line indicates $450 \mathrm{~nm}$, green line indicates $550 \mathrm{~nm}$, and red line indicates $700 \mathrm{~nm}$.

air mass, absorbing aerosol emitted from near local source and the vertical structure of the atmosphere.

\section{b. Optical characteristics classified by extinction Angström exponent}

The extinction Ångström exponent represents the relative contribution of larger and smaller size particles to the size distribution, being small when the rela- tive contribution of larger particles is great and large when the relative contribution of smaller particles is great. To investigate the dependence of aerosol characteristics on size distribution, we classified the data by the magnitude of the extinction Ångström exponent as follows: $-0.5<\alpha_{e x t} \leq 0.5,0.5<\alpha_{e x t} \leq 1.0,1.0$ $<\alpha_{\text {ext }} \leq 1.5,1.5<\alpha_{\text {ext }} \leq 2.0$, and $2.0<\alpha_{\text {ext }} \leq 2.5$.

Figure 12a shows the SSA plotted against the 
extinction Ångström exponent. As the extinction Ångström exponent increases, the SSA decreases, and this tendency is dependent on wavelength: at smaller extinction Angström exponents, the SSA decreases (absorption increases) at shorter wavelengths, and at larger extinction Angström exponents, the SSA decreases at longer wavelengths. At times when airborne mineral dust is abundant at the observation site, extinction Ångström exponents are less than 0.5 (Uchiyama et al. 2005). Therefore, this wavelength dependence of the SSA appears to be a response to mineral dust levels. In Tsukuba, a large fraction of extinction Ångström exponents was more than 1 and that of absorption Ångström exponents was about 1 . Therefore, the relative contribution of absorption to extinction coefficient increases at longer wavelengths.

Figure $12 \mathrm{~b}$ shows the relation between the extinction Ångström exponent and the asymmetry factor. When the extinction Ångström exponent is small, the relative contribution of larger particles to the size distribution is greater, and vice versa. Therefore, as the extinction Angström exponent increases, the asymmetry factor decreases. Furthermore, the wavelength dependence becomes weaker at smaller extinction Ångström exponents.

Figure 13 shows the derived volume size distributions $(\mathrm{d} V / \mathrm{d} \log r)$. For extinction Ångström exponents greater than 1 , the volume size distributions are unimodal with a peak at around $0.1 \mu \mathrm{m}$ radius. For extinction Ångström exponents less than 1, the retrieved volume size distributions are bimodal with peaks at around 0.1 and $2 \mu \mathrm{m}$. Furthermore, as the extinction Ångström exponent decreases, the fraction of larger particles in the size distribution increases. A similar bimodal volume size distribution has been documented from sky radiometer data at times of heavy airborne mineral dust (Tanaka et al. 1989; Shiobara et al. 1991; Uchiyama et al. 2005).

The estimated index of refraction is shown in Fig. 14. The real part of the refractive index is around 1.5, and the wavelength dependence is smaller in each case. The wavelength dependence of the imaginary part of the refractive index is dependent on the extinction Ångström exponent. For extinction Ångström exponents less than 1, the imaginary part decreases as wavelength increases, whereas at extinction Ångström exponents greater than 1.5, the imaginary part increases as wavelength increases. The imaginary part is less at smaller extinction Ångström exponents than at larger extinction Ångström exponents. The magnitude and wavelength dependence of the imaginary part of the refractive index at smaller extinction
Ångström exponents corresponds to the characteristics of mineral dust (Aoki et al. 2005).

\section{Conclusions}

Aerosol scattering and absorption coefficients have been continuously measured since January 2002 at Tsukuba, Japan, using an integrating nephelometer and absorption photometers. We analyzed this 10 -year data record to extract aerosol characteristics.

We investigated aerosol characteristics including scattering and absorption coefficients, the SSA, the asymmetry factor, the extinction Ångström exponent, and the absorption Ångström exponent. Many of these characteristics had seasonal variations as well as longterm trends that were significant at the $95 \%$ confidence level.

Both extinction and absorption coefficients had statistically significant decreases $(95 \%$ confidence level) between 2002 and 2013: the trend for extinction coefficient at $550 \mathrm{~nm}$ was $-1.5 \times 10^{-6} \mathrm{~m}^{-1}$ year $^{-1}$ and that of absorption coefficient at $530 \mathrm{~nm}$ was $-5.4 \times$ $10^{-7} \mathrm{~m}^{-1}$ year ${ }^{-1}$. Scattering coefficients at $550 \mathrm{~nm}$ also decreased over this period, but the level of statistical significance was lower: the trend was $-8.8 \times 10^{-7} \mathrm{~m}^{-1}$ year $^{-1}$. These decreasing trends are similar to those previously obtained from analysis of radiometer data.

The SSA at $550 \mathrm{~nm}$ increased by $7.4 \times 10^{-3}$ year $^{-1}$ from 2002 to 2013 and by $6.9 \times 10^{-3}$ year $^{-1}$ from 2006 to 2013. These trends were significant at the 95 $\%$ confidence level. The SSA was high in spring and early summer and low in late autumn and early winter. These trends and seasonal variations are similar to those previously obtained from analysis of radiometer data.

The asymmetry factor trends were not significant at the $95 \%$ confidence level. The extinction Angström exponent increased by $1.4 \times 10^{-2}$ year $^{-1}$, which was significant at the $95 \%$ confidence level.

The absorption Ångström exponent values were about 1.0 and showed seasonal variation, with larger values in late autumn and early winter and smaller values in summer. The increase in late autumn and early winter is explained by local biomass burning. The absorption Ångström exponent increased from 2006 to 2013 by $2.1 \times 10^{-2}$ year $^{-1}$, probably because of reductions in motor vehicle aerosols with low absorption Ångström exponents.

Using data from 2006 to 2013, the frequency distributions of aerosol properties were investigated. In this period, absorption coefficients were measured by three-wavelength PSAP3 $\lambda$.

The most frequent value of extinction coefficients 


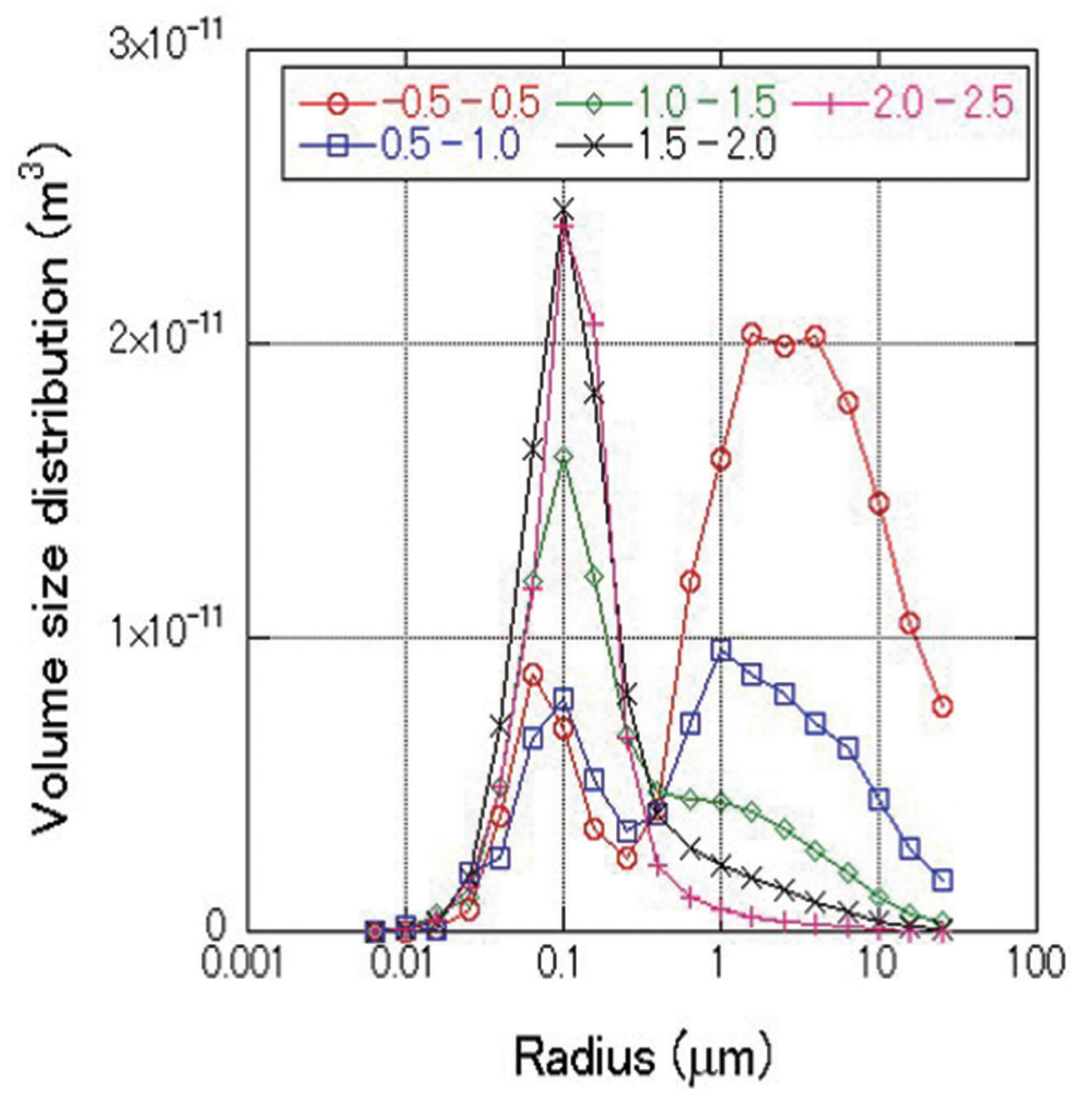

Fig. 13. Relation between extinction Ångström exponent and volume size distribution.

\section{Real part}

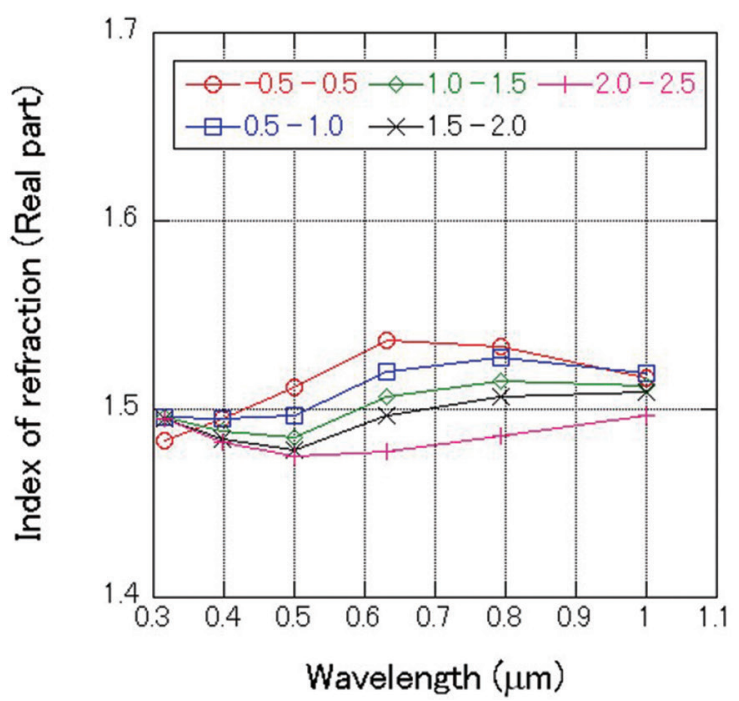

Imaginary part

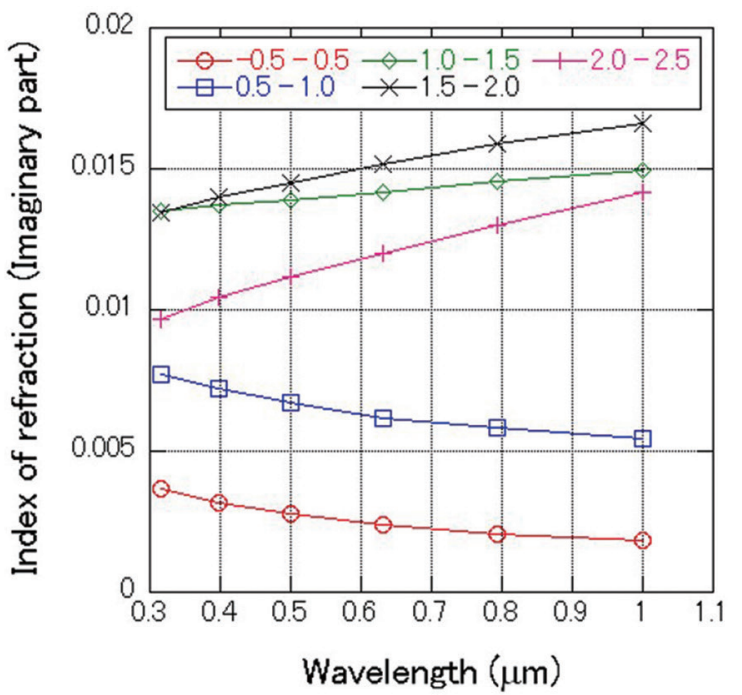

Fig. 14. Relation between extinction Ångström exponent and refractive index. (a) real part of refractive index, (b) imaginary part of refractive index. 
was $25 \times 10^{-6} \mathrm{~m}^{-1}$, and most values were below $200 \times$ $10^{-6} \mathrm{~m}^{-1}$. The most frequent value of absorption coefficients was $3.0 \times 10^{-6} \mathrm{~m}^{-1}$, and most values were below $30 \times 10^{-6} \mathrm{~m}^{-1}$. The most frequent value in each season was not changed. The most frequent value of the SSA at $550 \mathrm{~nm}$ was 0.905 . There was a seasonal pattern, with the most frequent SSA values in spring, summer, autumn, and winter being 0.925, 0.925, 0.885 , and 0.875 , respectively. The most frequent value of asymmetry factor at $550 \mathrm{~nm}$ was 0.585 .

We also analyzed the dependence of aerosol characteristics on size distribution, as represented by the extinction Angström exponent. The SSA tended to decrease as the extinction Angström exponent increased, and this tendency depended on wavelength. These characteristics reflect the composition of the aerosol. At extinction Ångström exponents greater than 1 , the volume size distributions were unimodal with a peak at around $0.1 \mu \mathrm{m}$ radius, and at extinction Ångström exponents less than 1, the volume size distributions were bimodal with peaks at around 0.1 and $2 \mu \mathrm{m}$. The real part of the refractive index was around 1.5, and the wavelength dependence was smaller in each case. The wavelength dependence of the imaginary part of the refractive index was dependent on the extinction Ångström exponent. At extinction Ångström exponents less than 1, the imaginary part decreased as wavelength increased, and at extinction Ångström exponents greater than 1.5, the imaginary part increased as wavelength increased. The values of the imaginary part were smaller in the former case than in the latter case.

Aerosol characteristics estimated from multiwavelength integrating nephelometer and absorption photometer data in this study are consistent with those derived from radiometer data. Therefore, ground-based monitoring of aerosol optical properties is useful for monitoring aerosol characteristics and interpreting variations in the surface radiation budget. As optical properties depend on the composition and shape of aerosols, it is necessary to monitor these aspects of aerosols as well as their scattering and absorption coefficients.

\section{Acknowledgment}

We express our appreciation to two anonymous reviewers for their useful comments.

This study was partially supported by JSPS Grants-in-Aid for Scientific Research (19340139 and 22310015).

\section{References}

Anderson, T. L., D. S. Covert, S. F. Marshall, M. L. Laucks, R. J. Charlson, A. P. Waggoner, J. A. Ogren, R. Caldow, R. L. Holm, F. R. Quant, G. J. Sem, A. Wiedensohler, N. A. Ahlquist, and T. S. Bates, 1996: Performance characteristics of a high-sensitivity, three-wavelength, total scatter/backscatter nephelometer. J. Atmos. Oceanic. Technol., 13, 967-986.

Anderson, T. L., and J. A. Ogren, 1998: Determining aerosol radiative properties using the TSI 3563 integrating nephelometer. Aerosol Sci. and Technol., 29, 57-69.

Aoki, T., M. Mikami, A. Yamazaki, S. Yabuki, Y. Yamada, M. Ishizuka, F.-J. Zeng, W.-D. Gao, J.-Y. Sun, L.-C. Liu, M.-X. Zhou, 2005: Spectral albedo of desert surfaces measured in western and central China. $J$. Meteor. Soc. Japan, 83A, 279-290.

Bergstrom, R. W., P. Pilewskie, P. B. Russell, J. Redemann, T. C. Bond, P. K. Quinn, and B. Sierau, 2007: Spectral absorption properties of atmospheric aerosols. Atmos. Chem. Phys., 7, 5937-5943.

Bond, T. C., T. L. Anderson, and D. Campbell, 1999: Calibration and intercomparison of filter-based measurements of visible light absorption by aerosols. Aerosol Sci. Technol., 30, 582-600.

Bond, T. C., D. S. Covert, and T. Müller, 2009: Truncation and angular scattering corrections for absorbing aerosol in the TSI 3563 nephelometer. Aerosol Sci. and Technol., 43, 866-871.

Coen, C., M., E. Weingartner, S. Nyeki, J. Cozic, S. Henning, B. Verheggen, R. Gehrig, and U. Baltensperger, 2007: Long-term trend analysis of aerosol variables at the high-alpine site Jungfraujoch. J. Geophys. Res., 112, D13213, doi:10.1029/2006JD007995.

Dutton, E. G., D. W. Nelson, R. S. Stone, D. Longenecker, G. Carbaugh, J. M. Harris, and J. Wendell, 2006: Decadal variations in surface solar irradiance as observed in a globally remote network. J. Geophys. Res., 111, D19101, doi:10.1029/2005JD006901.

Gilgen, H., M. Wild, and A. Ohmura, 1998: Means and trends of shortwave irradiance at the surface estimated from global energy balance archive data. $J$. Climate, 11, 2042-2061.

Gilgen, H., A. Roesch, M. Wild, and A. Ohmura, 2009: Decadal changes of shortwave irradiance at the surface in the period from 1960 to 2000 estimated from global energy balance archive data. J. Geophys. Res., 114, D00D08, doi:10.1029/2008JD011383.

Hansen, J. E., and L. D. Travis, 1974: Light scattering in planetary atmospheres. Space Sci. Rev., 16, 527-610.

Heintzenberg, J., and R. J. Charlson, 1996: Design and Applications of the integrating nephelometer: A review. J. Atmos. Oceanic. Technol., 13, 987-1000.

Junker, C., S. G. Jennings, and H. Cachier, 2006: Aerosol light absorption in the North Atlantic: Trends and 
seasonal characteristics during the period 1989 to 2003. Atmos. Chem. Phys., 6, 1913-1925.

Kirchstetter, T. W., T. Novakov, and P. V. Hobbs, 2004: Evidence that the spectral dependence of light absorption by aerosols is affected by organic carbon. J. Geophys. Res., 109, D21208, doi:10.1029/2004JD004999.

Kudo, R., A. Uchiyama, A. Yamazaki, T. Sakami, and E. Kobayashi, 2010: From solar radiation measurements to optical properties: 1998-2008 trends in Japan. Geophys. Res. Lett., 37, L04805, doi:10.1029/2009GL041794.

Kudo, R., A. Uchiyama, A. Yamazaki, T. Sakami, and O. Ijima, 2011: Decadal changes in aerosol optical thickness and single scattering albedo estimated from ground-based broadband radiometers: A case study in Japan. J. Geophys. Res., 116, D03207, doi:10.1029/2010JD014911.

Kudo, R., A. Uchiyama, O. Ijima, N. Ohkawara, and S. Ohta, 2012: Aerosol impact on the brightening in Japan. J. Geophys. Res., 117, D07208, doi:10.1029/2011JD017158.

Lewis, K., W. P. Arnott, H. Moosmüller, and C. E. Wold, 2008: Strong spectral variation of biomass smoke light absorption and single scattering albedo observed with a novel dual-wavelength photoacoustic instrument. J. Geophys. Res., 113, D16203, doi:10.1029/2007JD009699.

Liepert, B. G., 2002: Observed reductions of surface solar radiation at sites in the United States and worldwide from 1961 to 1990. Geophys. Res. Lett., 29, 1421, doi:10.1029/2002GL014910.

Liou, K. N., 2002: An Introduction to Atmospheric Radiation, Second Edition Int. Geophysics Ser, 84, Academic Press, 583 pp.

Lohmann, U., and J. Feichter, 2005: Global indirect aerosol effects: A review. Atmos. Chem. Phys., 5, 715-737.

McComiskey, A., E. Andrews, D. Jackson, A. Jefferson, S. W. Kim, J. Ogren, P. Sheridan, and J. Wendell, 2004: Climate monitoring and diagnostics laboratory summary report. Summary Rep. No. 27 2002-2003, Schnell, R. C. (ed.), U.S. Dep. of Commerce, Washington, D. C., 58-96.

Müller, T., A. Nowak, A. Wiedensohler, P. Sheridan, M. Laborde, D. S. Covert, A. Marinoni, K. Imre, B. Henzing, J.-C. Roger, S. M. dos Santos, R. Wilhelm, Y.-Q. Wang, and G. de Leeuw, 2009: Angular illumination and truncation of three different integrating nephelometers; Implications for empirical, size-based corrections. Aerosol Sci. and Technol., 43, 581-586.

Nishizawa, T., S. Asano, A. Uchiyama, and A. Yamazaki, 2004: Seasonal variation of aerosol direct radiative forcing and optical properties estimated from ground - based solar radiation measurements. J. Atmos. Sci., 61, 57-72.

Ohmura, A., 2009: Observed decadal variations in surface solar radiation and their causes. J. Geophys. Res., 114, D00D05, doi:10.1029/2008JD011290.

Pinker, R. T., B. Zhang, and E. G. Dutton, 2005: Do satellites detect trends in surface solar radiation? Science, 308, 850-854.

Ramanathan, V., P. J. Crutzen, J. T. Kiehl, and D. Rosenfeld, 2001: Aerosols, climate, and the hydrological cycle. Science, 294, 2119-2124.

Russell, P. B., R. W. Bergstrom, Y. Shinozuka, A. D. Clarke, P. F. DeCarlo, J. L. Jimenez, J. M. Livingston, J. Redemann, O. Dubovik, and A. Strawa, 2010: Absorption angstrom exponent in AERONET and related data as an indicator of aerosol composition. Atmos. Chem. Phys., 10, 1155-1169.

Sheridan, P. J., D. J. Delene, and J. A. Ogren, 2001: Four years of continuous surface aerosol measurements from the Department of energy's atmospheric radiation measurement program southern great plains cloud and radiation testbed site. J. Geophys. Res., 106, 20735-20747.

Shiobara, M., M. Tanaka, T. Hayasaka, and T. Nakajima, 1991: Aerosol monitoring using a scanning spectral radiometer in Sendai, Japan. J. Meteor. Soc. Japan, 69, 57-70.

Tanaka, M., M. Shiobara, T. Nakajima, M. Yamano, and K. Arao, 1989: Aerosol optical characteristics in the yellow sand events observed in May, 1982 in Nagasaki : Part 1 observations. J. Meteor. Soc. Japan, 67, 267-278.

Uchiyama, A., 2014: Method to retrieve single scattering properties of aerosol using multi-wavelength scattering and absorption coefficients data measured by integrating nephelometer and absorption photometer. J. Meteor. Soc. Japan, 92A, 71-91.

Uchiyama, A., A. Yamazaki, H. Togawa, and J. Asano, 2005: Characteristics of aeolian dust observed by sky-radiometer in the Intensive Observation Period 1 (IOP1). J. Meteor. Soc. Japan, 83A, 291-305.

Wild, M., 2009: Global dimming and brightening: A review. J. Geophys. Res., 114, D00D16, doi:10.1029/2008JD011470.

Wild, M., A. Ohmura, H. Gilgen, and D. Rosenfeld, 2004: On the consistency of trends in radiation and temperature records and implications for the global hydrological cycle. Geophys. Res. Lett., 31, L11201, doi:10.1029/2003GL019188.

Wild, M., H. Gilgen, A. Roesch, A. Ohmura, C. N. Long, E. G. Dutton, B. Forgan, A. Kallis, V. Russak, and A. Tsvetkov, 2005: From dimming to brightening: decadal changes in solar radiation at earth's surface. Science, 308, 847-850.

Wild, M., A. Ohmura, and K. Makowski, 2007: Impact of global dimming and brightening on global warming. Geophys. Res. Lett., 34, L04702, doi:10.1029/2006GL028031.

Wild, M., J. Grieser, and C. Schär, 2008: Combined surface 
solar brightening and increasing greenhouse effect support recent intensification of the global land-based hydrological cycle. Geophys. Res. Lett., 35, L17706, doi:10.1029/2008GL034842.

Wild, M., B. Trüssel, A. Ohmura, C. N. Long, G. K. Langlo, E. G. Dutton, and A. Tsvetkov, 2009: Global dimming and brightening: An update beyond 2000. J. Geophys. Res., 114, D00D13, doi:10.1029/2008JD011382.
Yamamoto, G., and M. Tanaka, 1972: Increase of global albedo due to air pollution. J. Atmos, Sci., 29, 14051412.

Yang, M., S. G. Howell, J. Zhuang, and B. J. Huebert, 2009: Attribution of aerosol light absorption to black carbon, brown carbon, and dust in China - interpretations of atmospheric measurements during EASTAIRE. Atmos. Chem. Phys., 9, 2035-2050. 